\title{
Rhabdomyolysis Caused by Gefitinib Overdose: A Case Report
}

\author{
Shohei Obayashi, Katsuyoshi Tomomatsu, Mika Urata, Jun Tanaka, Kyoko Niimi, \\ Naoki Hayama, Tsuyoshi Oguma, Koichiro Asano and Yoko Ito
}

\begin{abstract}
:
Epidermal growth factor receptor (EGFR) tyrosine kinase inhibitors (TKIs) are common therapeutic agents for EGFR mutation-positive advanced non-small-cell lung cancer. There has been no report of rhabdomyolysis caused by an overdose of EGFR-TKIs. We herein review the existing literature on the subject and report a rare case of rhabdomyolysis due to an overdose of gefitinib, an EGFR-TKI.
\end{abstract}

Key words: EGFR-TKI, Rhabdomyolysis, Overdose

(Intern Med Advance Publication)

(DOI: 10.2169/internalmedicine.8168-21)

\section{Introduction}

Epidermal growth factor receptor (EGFR) tyrosine kinase inhibitors (TKIs), such as gefitinib, erlotinib, afatinib and osimertinib, are the first-line treatment for EGFR mutationpositive advanced non-small-cell lung cancer. Patients with lung cancer are reported to be highly likely to have depression and adjustment disorders, with a high standardized mortality rate from suicide (1). Unlike transvenous chemotherapy, oral anti-cancer drugs, such as EGFR-TKIs, carry a risk of overdose. In addition, although creatine kinase (CK) elevation was not reported in gefitinib, 8 cases $(0.08 \%)$ in the post-marketing surveillance study of erlotinib, 4 cases $(0.17 \%)$ in the international joint phase III study of afatinib and 4 cases $(0.7 \%)$ in the international joint phase III study of osimertinib showed elevated serum CK levels according to the pharmaceutical interview forms. However, little is known about the mechanisms of rhabdomyolysis caused by EGFR-TKIs.

We herein report a case of rhabdomyolysis caused by an overdose of gefitinib.

\section{Case}

A 69-year-old woman was treated with $250 \mathrm{mg}$ gefitinib every day for 1 year for EGFR exon 21 L858R point mutation-positive advanced lung adenocarcinoma [cT3N3M1 a stage IVA (PLU)]. She was hospitalized after a suicidal attempt with an overdose of gefitinib. While she had no history of mental illness, diazepam had been prescribed for anxiety symptoms.

Two days before her visit to the emergency room, she consumed 1,500 mg gefitinib and $8 \mathrm{mg}$ diazepam simultaneously. The next day, symptoms of nausea, vomiting, diarrhea, and bloody sputum appeared. Two days after the overdose, her son returned home and found her vomiting and mentally unstable, so he took her to our hospital. When she visited the emergency room, she showed tachycardia, hypertension, and tachypnea (heart rate, 116 beats/min; blood pressure, 167/95 $\mathrm{mmHg}$; respiratory rate, 24 breaths/min), but neither muscle pain nor muscle weakness. She was conscious, but a psychiatrist found that she had suicidal ideation and was depressed. Blood test results showed elevated creatine kinase (CK: 7,482 U/L) and myoglobin (1,613 ng/mL) levels, liver (AST 169 U/L, ALT 179 U/L) and kidney dysfunction (creatinine $0.99 \mathrm{mg} / \mathrm{dL}$ ), elevated amylase levels (1,039 U/L: salivary type 93\%) and elevated C-reactive protein (CRP: $9.03 \mathrm{mg} / \mathrm{dL}$ ) levels.

Chest computed tomography (CT) indicated that the primary tumor in the right upper lobe was smaller than prior to gefitinib treatment (Fig. 1a, b). The serum concentrations of gefitinib at 48 and $96 \mathrm{~h}$ after the overdosing were measured using liquid chromatography-mass spectrometry and were

Division of Pulmonary Medicine, Department of Medicine, Tokai University School of Medicine, Japan

Received: June 21, 2021; Accepted: September 12, 2021; Advance Publication by J-STAGE: October 26, 2021

Correspondence to Dr. Yoko Ito, itoy@tokai.ac.jp 
(a)
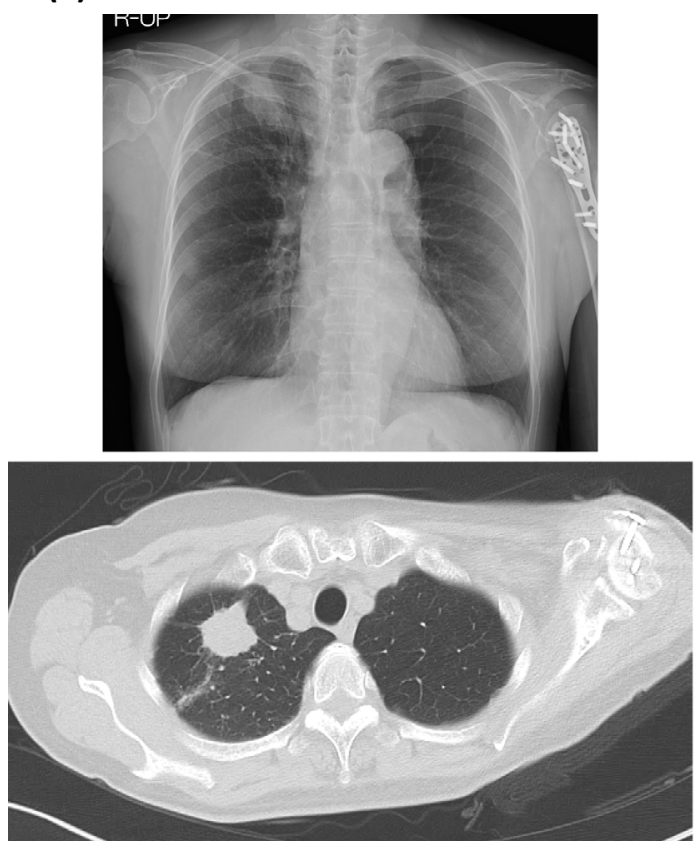

(b)

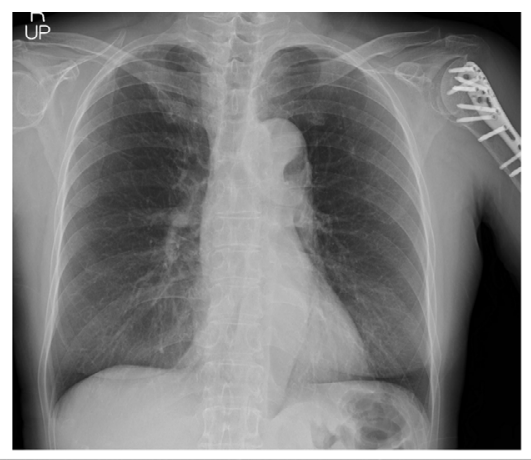

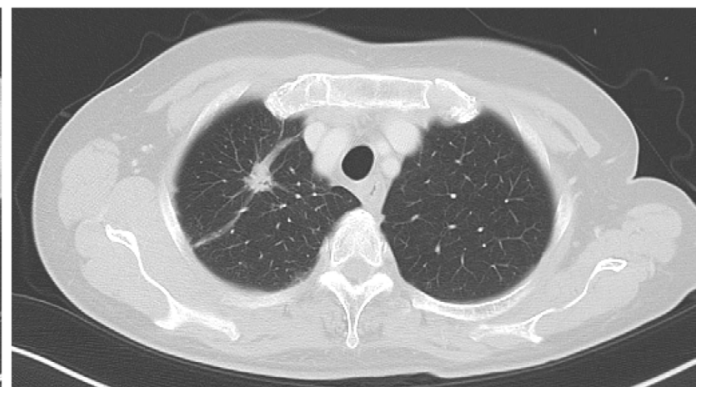

Figure 1. Chest X-Ray and CT scans: (a) before treatment with gefitinib, (b) when the patient visited emergency room.

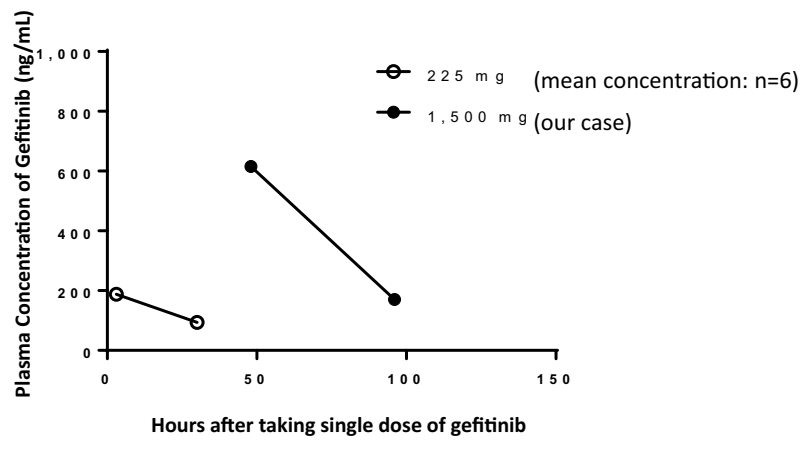

Figure 2. Time course line graph of gefitinib plasma concentration after taking a high dose (1,500 mg: our case) combined with those after taking a single dose of 225 mg gefitinib obtained from pharmaceutical interview form for gefitinib.

abnormally high (at $48 \mathrm{~h}: 615.7 \mathrm{ng} / \mathrm{mL}$, at $96 \mathrm{~h}: 170.1 \mathrm{ng} /$ $\mathrm{mL}$ ) compared to those recorded after taking a single dose $(225 \mathrm{mg})$ of gefitinib $\left(\mathrm{C}_{\max }: 188 \pm 120 \mathrm{ng} / \mathrm{mL}, \mathrm{T}_{\max }: 4.0\right.$ (3.012.0) $\mathrm{h}, \mathrm{t}_{1 / 2}: 30.1 \pm 4.6 \mathrm{~h}$ according to the pharmaceutical interview form) (Fig. 2). Based on these findings, she was diagnosed with acute drug poisoning due to gefitinib overdose, associated with rhabdomyolysis, liver injury and hyperamylasemia.

After extracellular fluid infusion was started at a rate of $2.5 \mathrm{~L} /$ day during hospitalization, the CK and amylase levels as well as the liver function immediately returned to normal (Fig. 3a, b). As her mental state recovered as well as her physical condition, she was discharged on the eighth day of hospitalization.

Two months after discharge, an increase in the size of her primary tumor was observed. As her mental status was sta- ble due to family support, afatinib was administered until progressive disease occurred, followed by gefitinib readministration. During the re-administration of EGFR-TKIs, her serum CK levels stayed within normal limits.

\section{Discussion}

This is the first case report of an EGFR-TKI overdose. Rhabdomyolysis caused by EGFR-TKIs is extremely rare. Indeed, to our knowledge, only three cases of regular-dose EGFR-TKI-induced rhabdomyolysis have been reported: one case report (2) and two cases in a conference abstract (3) (Table).

One study reported that the cancer-associated suicide rate was 27.5/100,000 persons per year in the United States, and the highest suicide risk was observed in patients with lung cancer (4). The median time to a suicide attempt in patients with lung cancer is 7 months after the diagnosis, which is earlier than for other cancers (4). In addition, a randomized controlled trial was conducted between a group of patients with lung cancer with metastasis who received only standard treatment and a group who received early palliative care in combination with standard treatment. The trial results showed a significantly improved quality of life, prolonged prognosis and reduction in symptoms of depression in the group who received early palliative care along with standard treatment (5). Given these findings, the active performance of mental intervention might have been needed in our case, although our patient had no history of mental illness, and her lung cancer condition had been stable.

Furthermore, most lung cancer patients are elderly, and some have various degrees of cognitive disorder. The num- 


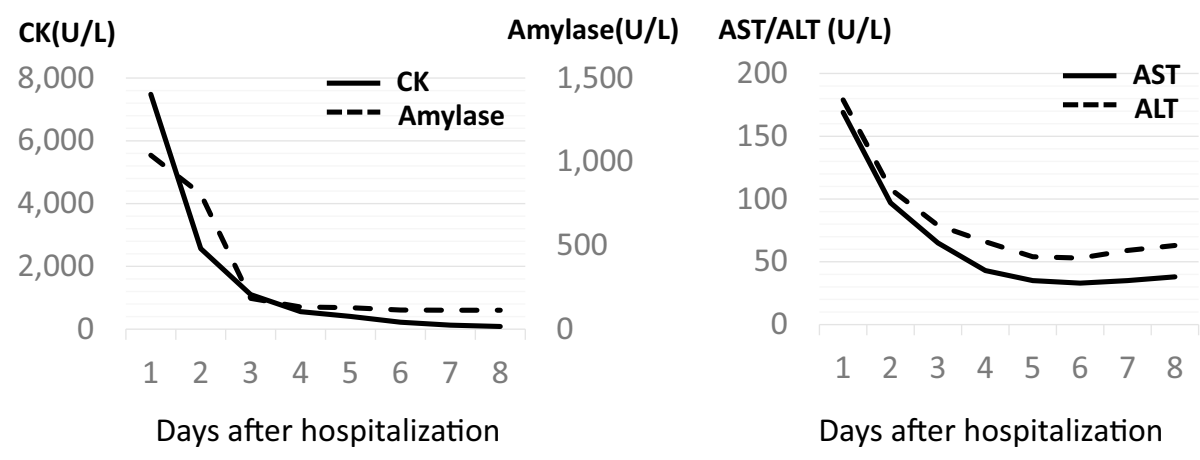

Figure 3. Time course line graph of CK, amylase (left), ALT, and AST concentrations after hospitalization (right).

Table.

\begin{tabular}{|c|c|c|c|c|c|c|c|c|}
\hline Case & Ref & Age & Gender & $\begin{array}{l}\text { EGFR- } \\
\text { mutation }\end{array}$ & $\begin{array}{l}\text { EGFR- } \\
\text { TKIs }\end{array}$ & Dose & $\begin{array}{l}\text { Days after starting } \\
\text { prescription of } \\
\text { EGFR-TKIs }\end{array}$ & $\begin{array}{c}\text { CK } \\
\text { (U/L) }\end{array}$ \\
\hline 1 & (3) & 69 & $M$ & $\begin{array}{l}\text { Exon } 19 \\
\text { deletion }\end{array}$ & Afatinib & unknown & 51 & 14,036 \\
\hline 2 & (3) & 80 & M & $\begin{array}{l}\text { Exon } 19 \\
\text { deletion }\end{array}$ & Afatinib & unknown & 27 & 2,859 \\
\hline 3 & (2) & 59 & $\mathrm{~F}$ & unknown & Erlotinib & $150 \mathrm{mg} /$ day & 29 & 1,215 \\
\hline 4 & $\begin{array}{l}\text { Our } \\
\text { case }\end{array}$ & 69 & $\mathrm{~F}$ & $\begin{array}{c}\text { Exon } 20 \\
\text { L858R } \\
\text { point } \\
\text { mutation }\end{array}$ & Gefitinib & $\begin{array}{c}250 \mathrm{mg} / \mathrm{day} \\
\text { and } \\
\text { Overdose } \\
1,500 \mathrm{mg}\end{array}$ & 258 & 7,482 \\
\hline
\end{tabular}

ber of oral anti-cancer drugs has recently grown. Therefore, to prevent intentional or accidental drug overdose, we must pay close attention to not only patients' psychological stress due to having cancer but also their cognitive function when prescribing oral anti-cancer drugs.

Drugs that lead to rhabdomyolysis include antidyslipidemia drugs, antibiotics and anesthetics (6). Among them, anti-dyslipidemia drugs represent the most reported drug group, but how they lead to rhabdomyolysis remains unclear. A few case reports of rhabdomyolysis due to drug overdose have been published $(7,8)$, but their pathogenesis also remains unclear. In our case, the serum CK and myoglobin concentrations upon emergency room admission were extremely high at over 40 and 20 times higher than the normal upper limit, respectively. Based on this, we suspect there are several possible mechanisms underlying the rhabdomyolysis that occurred in the current case. First, the possibility of a genetic background cannot be completely excluded. Factors influencing the pharmacokinetics and pharmacodynamics of drugs include drug transporters, drug metabolizing enzymes and the plasma protein-binding ratio. Gefitinib is a substrate for ABCG2, a drug transporter protein, and patients with a reduced ABCG2 activity due to a common genetic variant are at an increased risk for gefitinib-induced adverse events, such as diarrhea (9). In addition, published data show higher erlotinib concentrations at steady state and a higher risk of developing high grade toxicity in patients with the ABCB1 drug transporter 1236
TT-2677TT-3435TT genotype than other patients (10). Three previously reported cases developed rhabdomyolysis within two months after the start of their prescription $(2,3)$ (Table), suggesting that they might have a genetic background, while our case developed rhabdomyolysis at a later point of eight months. Therefore, our case suggests that there may be a risk of rhabdomyolysis at the time of overdose, even if there is no genetic predisposition. Second, a potential drug interaction between gefitinib and diazepam should be considered. In our case, a non-overdose amount of diazepam was consumed together with an overdose amount of gefitinib. Gefitinib undergoes extensive metabolism mainly via cytochrome P450 (CYP) 3A4 and CYP2D6 according to the gefitinib pharmaceutical interview form, and diazepam is also metabolized partly via CYP3A4 (11). A case of rhabdomyolysis due to the interaction of simvastatin with ticagrelor, both of which are metabolized via CYP3A4, was previously reported (12), but rhabdomyolysis caused by this type of drug-drug interaction is rare. These findings suggest that the combination of gefitinib with drugs metabolized via CYP3A 4 may carry a risk of rhabdomyolysis due to a relative deficiency of CYP3A4 and competitive interaction with drug transporter proteins. Third, as EGFR is expressed in skeletal muscles (13), a higher concentration of circulating gefitinib binds to EGFRs on skeletal muscle cells, which may lead to the necrosis and/or apoptosis of these cells and thereby release CK into the blood stream. 


\section{Conclusion}

Early palliative care intervention is desirable to prevent the excessive intake of oral anti-cancer medications in suicide attempts. In addition, rhabdomyolysis should be suspected in cases of EGFR-TKI overdosing.

The authors state that they have no Conflict of Interest (COI).

\section{References}

1. Akechi T, Okamura H, Nishiwaki Y, Uchitomi Y. Psychiatric disorders and associated and predictive factors in patients with unresectable nonsmall cell lung carcinoma: a longitudinal study. Cancer 92: 2609-2622, 2001.

2. Koršić M, Muršić D, Badovinac S, Božina N, Roglić M, Jakopović M, et al. Erlotinib-related rhabdomyolysis: the role of pharmacogenetics and drug-drug interaction. Cancer Chemother Pharmacol 76: 1317-1319, 2015

3. Ishikawa R, Yoneyama R, Miyajima K, Kimura M, Kohno T, Okinaka T, et al. 2 cases that Afatinib was considered as a cover suspicion medicine for rhabdomyolysis. Japanese Journal of Lung Cancer 56: 663, 2016.

4. Rahouma M, Kamel M, Abouarab A, Eldessouki I, Nasar A, Harrison $\mathrm{S}$, et al. Lung cancer patients have the highest malignancy-associated suicide rate in USA: a population-based analysis. Ecancermedicalscience 12: 859, 2018.

5. Temel JS, Greer JA, Muzikansky A, Gallagher ER, Admane S, Jackson VA, et al. Early palliative care for patients with metastatic non-small-cell lung cancer. N Engl J Med 363: 733-742, 2010.

6. Warren JD, Blumbergs PC, Thompson PD. Rhabdomyolysis: a review. Muscle Nerve 25: 332-347, 2002.

7. Santana NO, Góis AF. Rhabdomyolysis as a manifestation of clomipramine poisoning. Sao Paulo Med J 131: 432-435, 2013.

8. Karaoulanis SE, Syngelakis M, Fokas K. Rhabdomyolysis after lamotrigine overdose: a case report and review of the literature. Ann Gen Psychiatry 15: 6, 2016.

9. Cusatis G, Gregorc V, Li J, Spreafico A, Ingersoll RG, Verweij J, et al. Pharmacogenetics of ABCG2 and adverse reactions to gefitinib. J Natl Cancer Inst 98: 1739-1742, 2006.

10. Hamada A, Sasaki J, Saeki S, Iwamoto N, Inaba M, Ushijima S, et al. Association of $\mathrm{ABCB} 1$ polymorphisms with erlotinib pharmacokinetics and toxicity in Japanese patients with non-small-cell lung cancer. Pharmacogenomics 13: 615-624, 2012.

11. Olkkola KT, Ahonen J. Midazolam and other benzodiazepines. Handbook of experimental pharmacology. $\star \star \star \star \star \star \star$ : 335360, 2008.

12. Danielak D, Karaźniewicz-Łada M, Główka F. Assessment of the Risk of Rhabdomyolysis and Myopathy During Concomitant Treatment with Ticagrelor and Statins. Drugs 78: 1105-1112, 2018.

13. Ciano M, Mantellato G, Connolly M, Paul-Clark M, Willis-Owen $\mathrm{S}$, Moffatt MF, et al. EGF receptor (EGFR) inhibition promotes a slow-twitch oxidative, over a fast-twitch, muscle phenotype. Sci Rep 9: 9218, 2019.

The Internal Medicine is an Open Access journal distributed under the Creative Commons Attribution-NonCommercial-NoDerivatives 4.0 International License. To view the details of this license, please visit (https://creativecommons.org/licenses/ by-nc-nd/4.0/).

(C) The Japanese Society of Internal Medicine Intern Med Advance Publication 